Article

\title{
Indoor and Outdoor Concentrations of Particulate Matter in an Airport Terminal Building: A Pilot Study at Soekarno-Hatta International Airport in Indonesia
}

\author{
Amy Kim * ${ }^{\mathbb{C}}$, Lysandra Medal $\mathbb{D}^{\mathbb{D}}$, Shuoqi Wang $(\mathbb{D}$ and Timothy Larson \\ Department of Civil and Environmental Engineering, University of Washington, Campus Box 352700, Seattle, \\ WA 98195, USA; medal@uw.edu (L.M.); shuoqw@uw.edu (S.W.); tlarson@uw.edu (T.L.) \\ * Correspondence: amyakim@uw.edu; Tel.: +1-206-685-0228
}

Received: 9 January 2020; Accepted: 4 February 2020; Published: 7 February 2020

check for updates

\begin{abstract}
The air quality inside airport terminal buildings is a lesser studied area compared to ambient air quality at the airport. The contribution of outdoor particulate matter (PM), aircraft traffic, and passenger traffic to indoor PM concentration is not well understood. Using the largest airport in Southeast Asia as the study site (extends 17.9 square kilometers), the objective of this paper is to conduct a preliminary analysis to examine the mass concentrations of fine particles, including $\mathrm{PM}_{1}$ and $\mathrm{PM}_{2.5}$, and coarse particles $\mathrm{PM}_{2.5-10}$ inside a four-story terminal building spanning 400,000 square meters in Jakarta, Indonesia. The results showed the indoor/outdoor (I/O) ratio of 0.42 for $\mathrm{PM}_{1}$ with 15-min time lag and 0.33 for $\mathrm{PM}_{2.5}$ with 30-min time lag. The aircraft traffic appeared to have a significant impact on indoor $\mathrm{PM}_{1}$ and $\mathrm{PM}_{2.5}$, whereas the passenger traffic showed an influence on indoor $\mathrm{PM}_{2.5-10}$.
\end{abstract}

Keywords: airport; terminal building; particulate matter; indoor air quality; building operation; field measurement

\section{Introduction}

The modern airport is a complex system with various types of facilities. Some components of the airport include air traffic control facilities, airfield including approach zones, a terminal complex, a utility communications network, supporting and service facilities, and ground access system [1]. Among them, the terminal buildings are unique in that they usually operate on a 24-h basis throughout the year and directly interact with majority of the passengers and airport employees.

In recent years, the importance of air quality assessment at the airport has gradually been acknowledged. A number of studies on air quality have been conducted in various facilities at airports around the world. Typical air quality parameters include total volatile organic compounds (TVOC), ultrafine particles (UFP) (particle diameters are less than $0.1 \mu \mathrm{m}$ ), fine particles (FP) or $\mathrm{PM}_{2.5}$ (particle diameters are less than $2.5 \mu \mathrm{m}$ ), and $\mathrm{PM}_{10}$ (particle diameters are less than $10 \mu \mathrm{m}$ ). For example, the TVOC and other gas pollutants were evaluated inside the control tower by Helmis et al. [2], Mokalled et al. [3], and Tsakas and Siskos [4]. Helmis et al. [2] also measured the indoor $\mathrm{PM}_{2.5}$ and $\mathrm{PM}_{10}$ mass concentration in the control tower [2]. Lee et al. [5] and Kungskulniti et al. [6] used $\mathrm{PM}_{2.5}$ as a parameter to assess indoor air quality in airport smoking rooms. More studies can be found on ambient air quality at or near the airport. Hsu et al. $[7,8]$ monitored the UFP level near runways at two U.S. airports to evaluate the impact of aircraft emissions on ambient air quality. Stacey [9] provided a most recent review of UFP related studies conducted at or near the airport with a focus on aircraft emission. Other studies have looked at particle size distributions in the ambient air near the airports, such as in Hudda et al. [10], Masiol et al. [11,12], and Fanning et al. [13]. However, indoor air quality 
studies inside the airport terminal buildings are still limited for good reasons. Access to terminals and gates typically requires a thorough security check. Only passengers with boarding passes can wait by the entrance. Researchers with single-use escort passes still need to be accompanied by the airport security personnel to obtain measurements. Furthermore, obtaining the pre-approval from regulatory agencies adds another layer of complexity during the preparation phase of gaining permission to access the study site. These hurdles often act as discouragement for researchers during site selection of indoor air quality studies.

The airport terminal buildings experience a high fluctuation in the number of passengers that move through various parts of the building as well as the auxiliary spaces. Studies have shown that human activities, such as walking, often lead to particle resuspension which is an important indoor source of particulate matter $[14,15]$. Aircraft also generate a significant amount of particulate matter [16] as they idle near the ramps, taxi off the runway, and land onto the taxiways, which could infiltrate the building envelope and affect the air quality inside the terminal. Previous studies of airport workers have shown some evidence of correlation between chronic adverse respiratory symptoms and exposure to aviation fuel or jet stream exhaust [17,18]. Møller et al. [19] measured the exposure to UFP for five occupational groups at the airport. Workers who resided in the terminal buildings were considered a low exposure group or control group in these studies compared to other workers whose activities were outdoor or in closer proximity to aircraft. However, passengers spend most of their time at the airport inside the terminal buildings. It is equally important to understand the air quality inside the terminal building as opposed to other parts of the airport. Two recent studies by Zanni et al. [20] and Ren et al. [21] have examined the FP concentrations in airport terminal buildings in Italy and China, respectively. Other air quality parameters measured in the studies include TVOC [20] and UFP [21]. Whereas Zanni et al. concluded that the building's ventilation system appeared to be efficient in terms of filtration [20], Ren et al. demonstrated that the building failed to provide sufficient protection for passengers from $\mathrm{PM}_{2.5}$ and UFP exposures [21]. Yet, neither study included the coarse particles $\mathrm{PM}_{2.5-10}$ in the assessment. Brunekreef and Forsberg [22] have discussed the epidemiological evidence for effects of coarse particles on health and emphasized the importance of studying and regulating coarse particles separately from fine particles. A recent study by Deng et al. [23] found that coarse particles generated by crustal sources might have adverse health effects as strong as those of fine particles generated from combustion sources.

The objective of this paper was to conduct a pilot study with limited data to examine the mass concentrations of fine particles including $\mathrm{PM}_{1}$ and $\mathrm{PM}_{2.5}$, and coarse particles $\mathrm{PM}_{2.5-10}$ inside Terminal 3 of the Soekarno-Hatta International Airport (SHIA) in Jakarta. The feasibility of estimating particle infiltration using time-lagged regression was evaluated. In addition, the effect of aircraft and passenger traffic on the concentration of fine and coarse particles was investigated.

\section{Materials and Methods}

\subsection{Study Site}

SHIA is Indonesia's most prominent international airport that serves the greater Jakarta area. This airport is in Benda, Tangerang, $20 \mathrm{~km}$ northwest of Central Jakarta. SHIA is the largest airport in Southeast Asia, the most active in the southern hemisphere [24], and the seventh most connected airport in the world, functioning as a "mega hub" [25]. This airport handled more than 63 million passengers in 2017. The airport extends 17.9 square kilometers with three main terminal buildings. Terminal 1, 2, and 3 were opened in 1985, 1991, and 2016 respectively. Terminal 3 (T3) was selected as the study site. It is a four-story building with 3290 full-time employees and 456 part-time employees. Figure 1 shows the sampling location where the objective air quality measurements were obtained. 


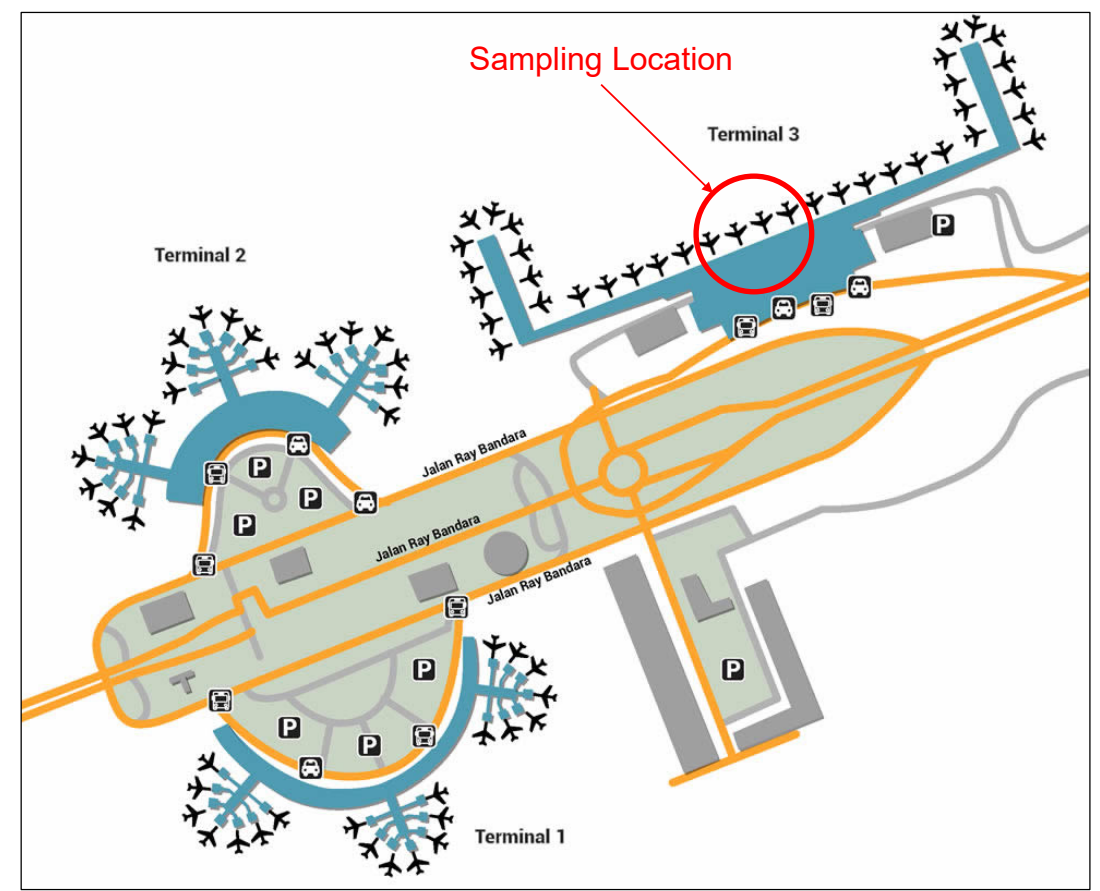

Figure 1. Location of field measurement in the center of Terminal 3 (Image source: https:/ /www. airportshuttles.com/cgk-airport-terminals.php).

This study required an extensive approval process involving five different airport authorities. The approval prior to the research team's arrival was handled by the Airport Management Center. It included online and physical submission of the research proposal and follow-up communications with the Human Resources and General Affairs Department to obtain the official approval letter to conduct air quality measurement from 31 January to 20 February 2019. Upon arrival, a formal meeting was conducted with the officer in charge (OIC) team and the airport mechanical engineers who were responsible for the operation and maintenance of the Terminal 3 building. This was a critical meeting where the airport operation team provided a secondary site-specific approval for the data collection. The research team discussed the objectives of the study which facilitated the identification of the optimal locations for indoor and outdoor air quality measurements. The daily access to the study site included passing multiple security checkpoints and areas beyond the checkpoints required escort of at least two OIC employees. An access flow chart is shown in Figure 2.

\subsection{Data Collection}

\subsubsection{Primary Data}

Two units of the Particles Plus 7302-AQM Air Quality Monitor [26] were used to measure the indoor and outdoor particle mass concentrations. The monitor used long-life laser diode technology to detect particles in the range of $0.3-25 \mu \mathrm{m}$ and was calibrated by the manufacturer. The two monitors were programmed to count the particles in a two-minute air sample at a flow rate of 2.83 liters per minute every five minutes.

The indoor and outdoor PM concentrations were measured at two sampling locations in this study, as shown in Figure 3. The indoor location was near one of the return air grilles in the boarding area. To keep the monitor in a secure location and from outdoor elements, the outdoor air was sampled through 10 feet of Bev-A-Line $X X^{\circledR}[27]$ tubing which had a smooth inner lining that was appropriate for high-purity air sampling applications. 


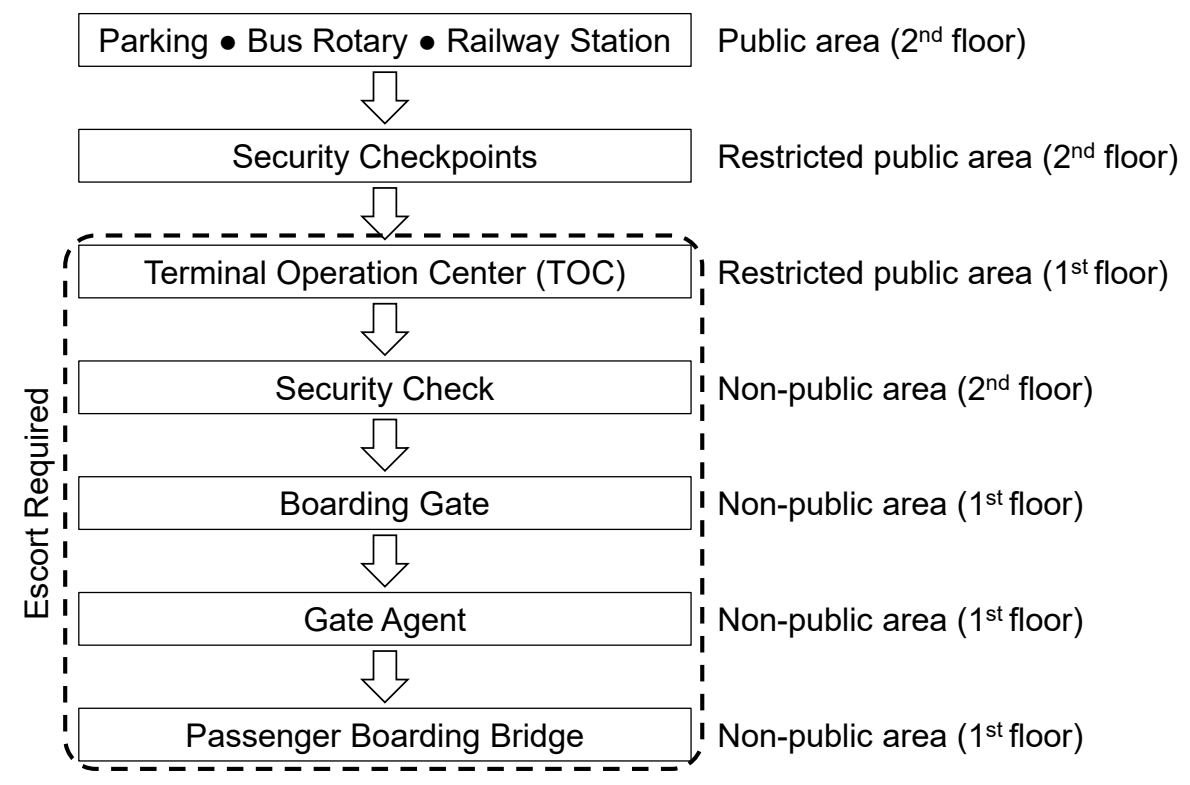

Figure 2. Flow chart of daily access to the study site.

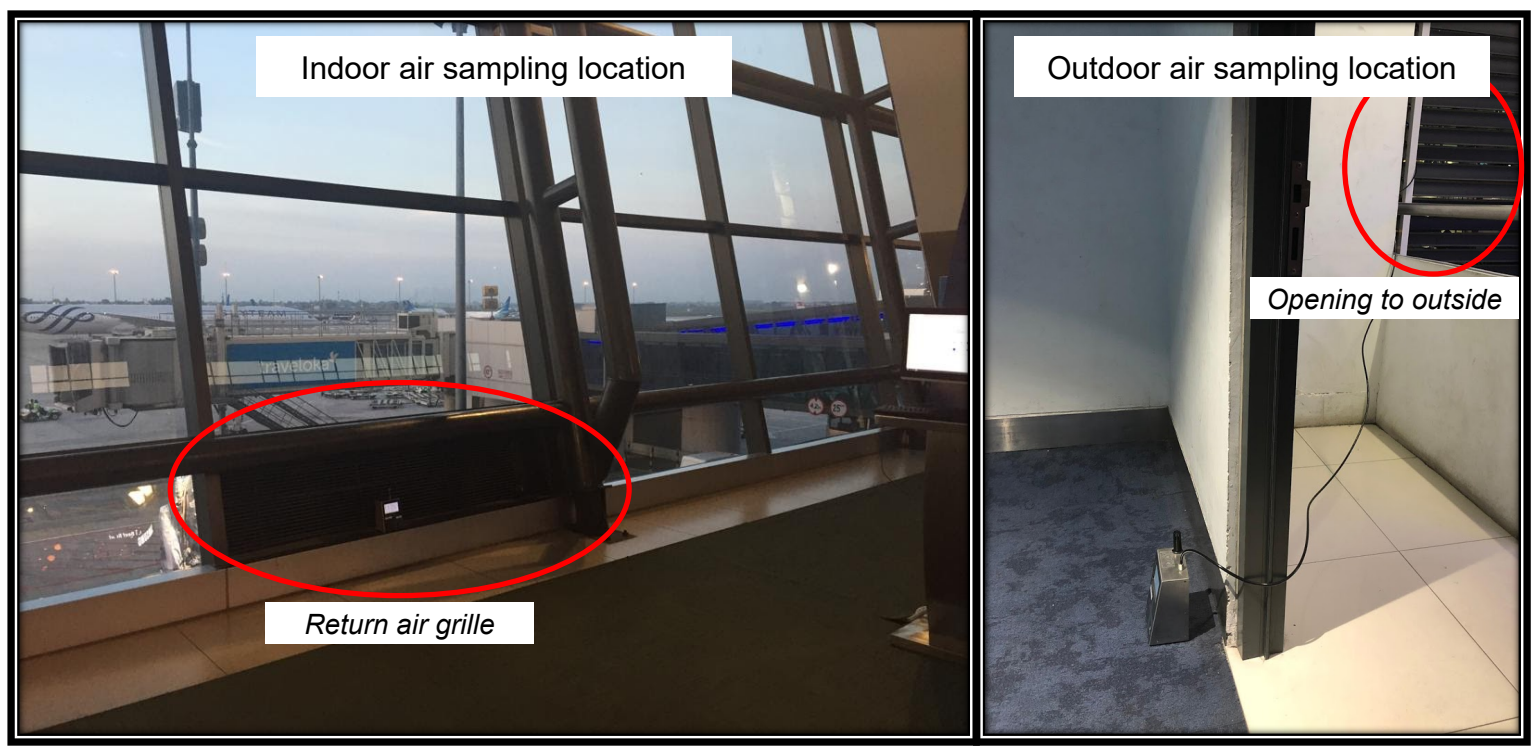

Figure 3. Sampling locations of the indoor and outdoor air.

\subsubsection{Secondary Data}

The weather data at the airport were obtained from the Indonesia Meteorology, Climatology, and Geophysical Agency (BMKG) [28] at 1-h intervals, as well as from Weather Underground [29] in 30-min intervals. Data from Weather Underground were used for analysis given the finer resolution. Previous studies have shown that light-scattering particle measurement devices are subject to error at high relative humidities [30-32]. Therefore, the measurements conducted when outdoor relative humidity (RH) was above $90 \%$ were excluded from further analysis. The remaining measurement sessions were listed in Table 1 . The total numbers of arriving and departing aircraft and passengers each hour were also provided by the airport.

The heating, ventilation, and air conditioning (HVAC) system at Terminal 3 operates $24 \mathrm{~h}$ a day throughout the week. The central air conditioning system includes the chillers, pumps, cooling towers, and air handling units (AHUs). Water, which is used as the medium, is cooled in the chiller unit and then distributed to the AHUs through the pumps. A blower on the AHU side supplies the cool air 
to multiple rooms in the terminal with an average air exchange rate of $70,000 \mathrm{~m}^{3} / \mathrm{h}$. The central air conditioning system consists of five units with a capacity of 2100 ton of refrigeration each. The AHUs are equipped with Dacron ${ }^{\circledR}$ filter rolls as well as framed and washable filter media. The Dacron ${ }^{\circledR}$ filters have high resistance to stretching in both wet and dry environments as well as to chemicals and abrasion [33]. The framed filters are cleaned monthly at the minimum as part of the HVAC maintenance schedule and replaced every year or when they are worn out (see Figure 4).

Table 1. Terminal 3 air quality measurement schedule.

\begin{tabular}{cccc}
\hline Session & Measurement Date & Arrive & Depart \\
\hline I & 2 February 2019 & 4:00 p.m. & 10:00 p.m. \\
II & 2 March 2019 & 6:00 p.m. & 11:00 p.m. \\
\hline
\end{tabular}

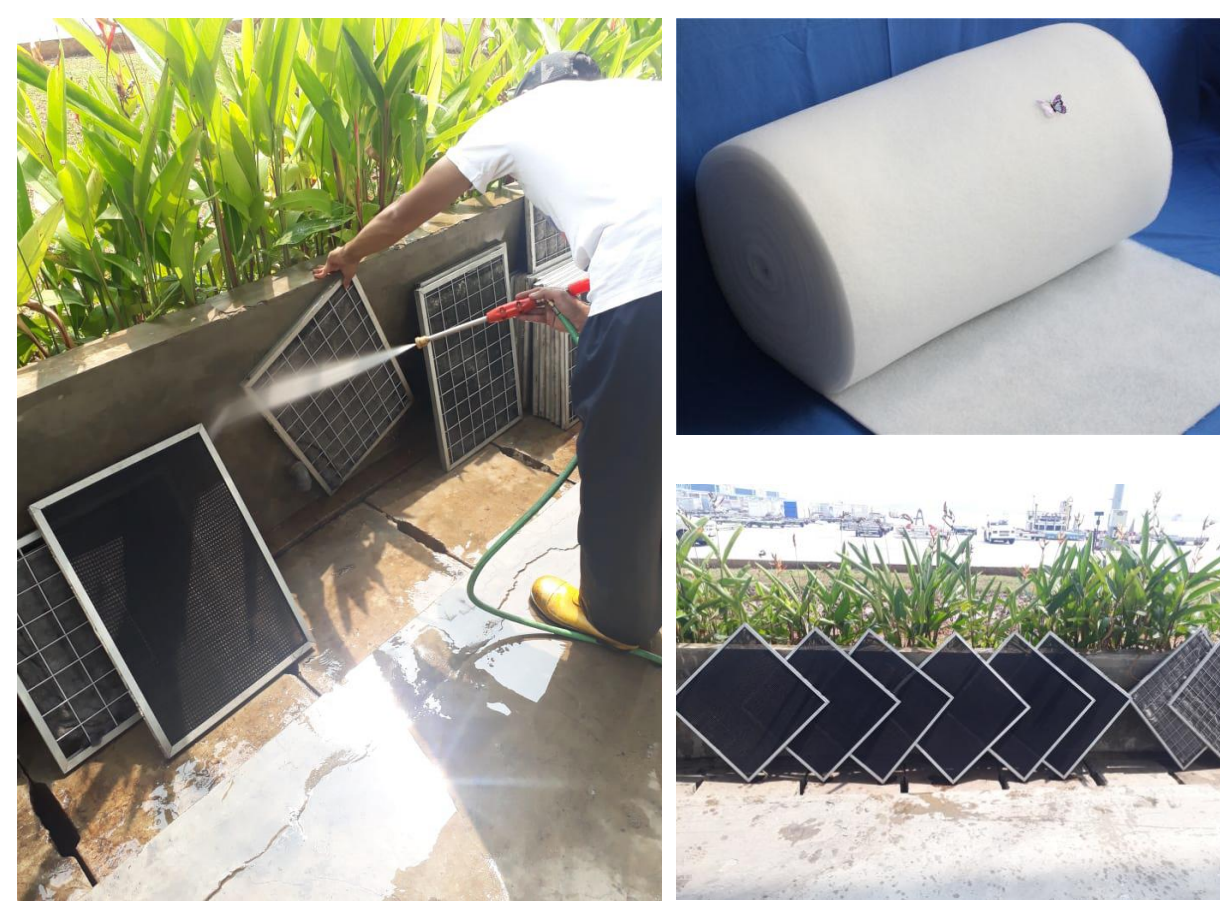

Figure 4. Filters being cleaned at the terminal.

\subsection{Data Analysis}

\subsubsection{Particle Mass Concentration Estimate}

The particles sampled by the monitor were divided into three groups for analysis based on the particle diameter; i.e., $\mathrm{PM}_{1}, \mathrm{PM}_{2.5}$, and $\mathrm{PM}_{2.5-10}$. The particle numbers recorded for each group were converted into mass concentration using the particle density of $2.2 \mathrm{~g} / \mathrm{cm}^{3}$, as reported by Hasheminassab et al. [34] in an ambient fine and coarse particles study conducted in Los Angeles. The calibration factor was kept at 1 , as used by the manufacturer.

Because the actual air change rate of the terminal building was unknown, the mass concentration was averaged over a 15-min interval based on the requirement of the Indonesian National Standardization SNI 03-6572:2001 [35] and the Jakarta Green Building User Guide [36]; i.e., four air exchanges per hour for lobby and corridor areas. The 15-min average was then smoothed using a simple moving average; i.e., for each observation $x_{t}$ at time $t$, the smoothed data point $\overline{x_{t}}$ is given by Equation (1):

$$
\overline{x_{t}}=\frac{x_{t-1}+x_{t}+x_{t+1}}{3}
$$


The smoothed indoor and outdoor mass concentrations of the different particle size groups are shown in Figures 5-7 for the two measurement sessions.

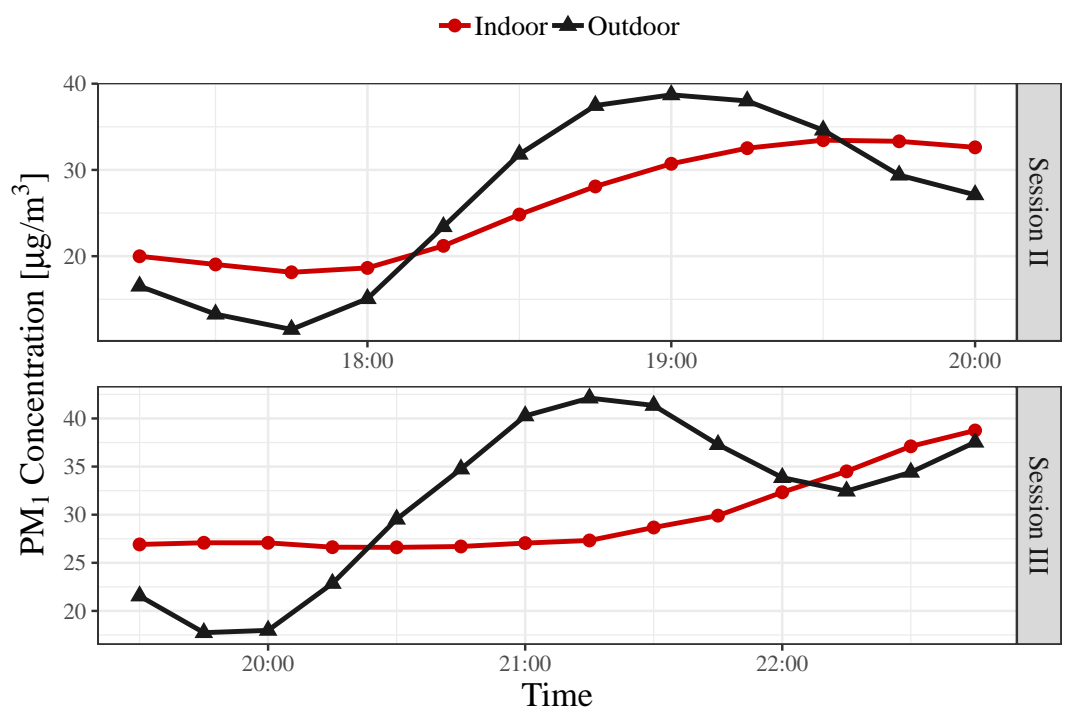

Figure 5. Indoor and outdoor $\mathrm{PM}_{1}$ mass concentration time series.

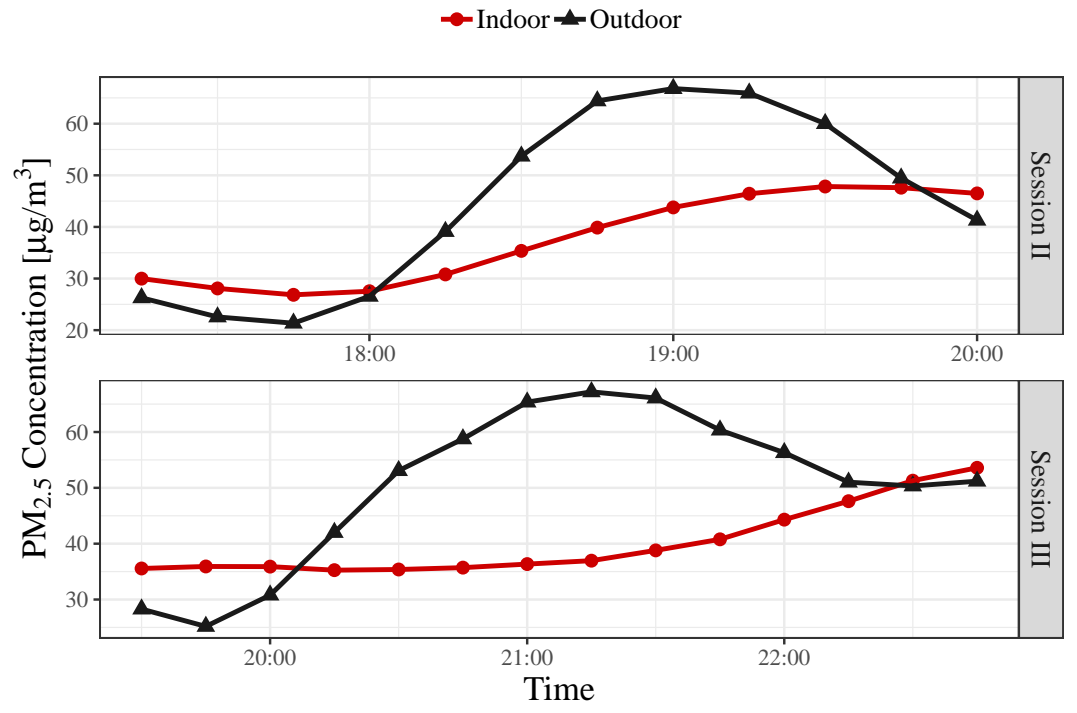

Figure 6. Indoor and outdoor $\mathrm{PM}_{2.5}$ mass concentration time series.

\subsubsection{Statistical Methods}

The statistical tests and regression analysis presented in this paper have been conducted using $\mathrm{R}$ [37]. The indoor and outdoor PM concentration data were tested for normality using the Shapiro-Wilk normality test [38]. Based on the normality test results, the Paired Sample $t$-test or Mann-Whitney U test was used to compare the difference of indoor and outdoor PM concentration levels.

The effects of aircraft and passenger traffic on the indoor particulate concentration were evaluated using analysis of covariance (ANCOVA). The aircraft and passenger traffic were converted to categorical factors, whereas the indoor and outdoor PM concentrations were included as continuous variables.

The particle indoor/outdoor (I/O) ratio was calculated for $\mathrm{PM}_{1}$ and $\mathrm{PM}_{2.5}$ using linear regression. Given that the infiltration of outdoor particles is often not instantaneous [39-41], the regression analysis was performed with a time lag. 


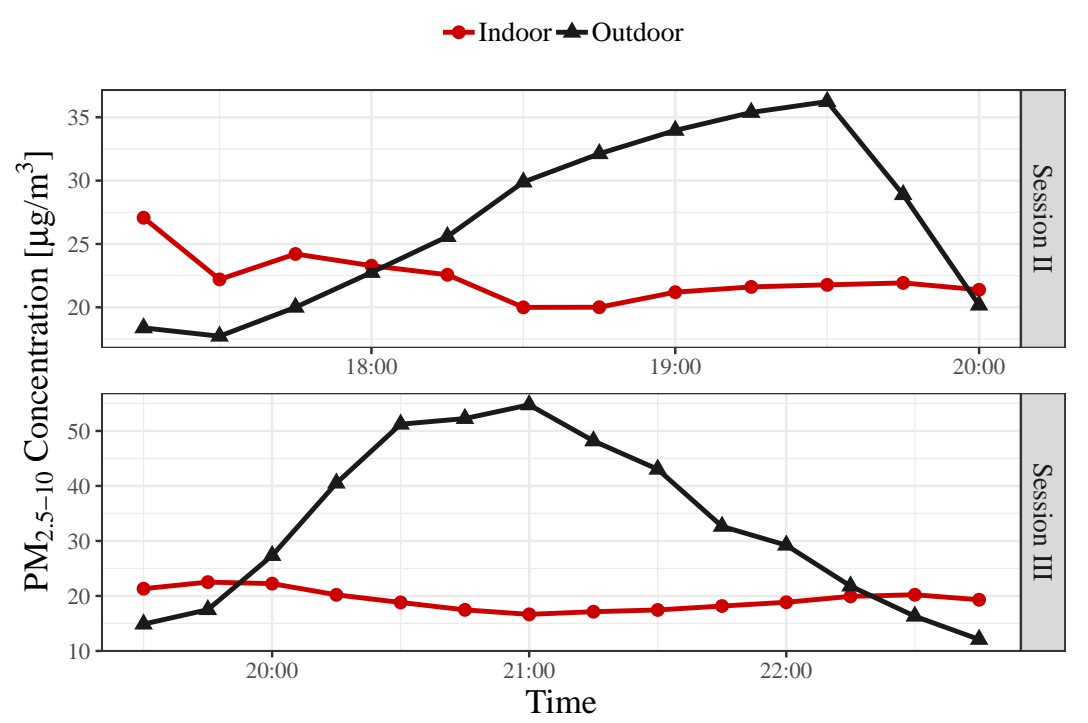

Figure 7. Indoor and outdoor $\mathrm{PM}_{2.5-10}$ mass concentration time series.

\section{Results}

\subsection{Descriptive Statistics}

The descriptive statistics of the 15-min average mass concentration of the indoor and outdoor particles for the three size groups are summarized in Table 2 and also illustrated in Figure 8 . The indoor and outdoor particle mass concentration data were tested for normality using the Shapiro-Wilk normality test [38]. The test statistic $W$ and corresponding $p$-value are summarized in Table 3.

Table 2. Descriptive statistics of the indoor and outdoor particle mass concentration $\left(\mu \mathrm{g} / \mathrm{m}^{3}\right)$.

\begin{tabular}{cccccc}
\hline Location & Particle Size & Min & Mean & Max & SD \\
\hline \multirow{4}{*}{ Indoor } & $\mathrm{PM}_{1}$ & 18.13 & 28.04 & 38.75 & 5.54 \\
& $\mathrm{PM}_{2.5}$ & 26.85 & 39.00 & 53.59 & 7.47 \\
& $\mathrm{PM}_{2.5-10}$ & 16.65 & 20.67 & 27.07 & 2.39 \\
\hline \multirow{4}{*}{ Outdoor } & $\mathrm{PM}_{1}$ & 11.51 & 29.25 & 42.12 & 9.50 \\
& $\mathrm{PM}_{2.5}$ & 21.35 & 47.82 & 67.20 & 15.70 \\
& $\mathrm{PM}_{2.5-10}$ & 12.09 & 30.11 & 54.74 & 12.31 \\
\hline
\end{tabular}

Table 3. Shapiro-Wilk normality test results.

\begin{tabular}{cccccc}
\hline \multirow{2}{*}{ Particle Size } & \multirow{2}{*}{ Sample Size } & \multicolumn{2}{c}{ Indoor } & \multicolumn{2}{c}{ Outdoor } \\
\cline { 3 - 6 } & & $W$ & $p$-Value & $W$ & $p$-Value \\
\hline $\mathrm{PM}_{1}$ & 26 & 0.955 & 0.298 & 0.920 & $0.045^{*}$ \\
$\mathrm{PM}_{2.5}$ & 26 & 0.951 & 0.251 & 0.898 & 0.014 \\
$\mathrm{PM}_{2.5-10}$ & 26 & 0.966 & 0.528 & 0.941 & 0.140 \\
\hline \multicolumn{4}{c}{ * Normality hypothesis rejected at $\alpha=0.05}$.
\end{tabular}

Because the outdoor $\mathrm{PM}_{1}$ and $\mathrm{PM}_{2.5}$ were not normally distributed, the nonparametric Mann-Whitney U test (or Wilcoxon Rank-Sum test) was performed to examine the difference of mass concentrations between the indoor and outdoor $\mathrm{PM}_{1}$ and $\mathrm{PM}_{2.5}$, whereas the paired sample $t$-test was used for the indoor and outdoor $\mathrm{PM}_{2.5-10}$. The Mann-Whitney $U$ test showed no significant difference between indoor and outdoor $\mathrm{PM}_{1}(p$-value $=0.532)$. These particles are usually difficult to be filtered by the HVAC system, even with higher minimum efficiency reporting value (MERV) rated filters due to their small size. However, the indoor $\mathrm{PM}_{2.5}$ and $\mathrm{PM}_{2.5-10}$ particles appeared to be at a 
much lower concentrations than outdoors, and the differences were statistically significant $\left(\mathrm{PM}_{2.5}\right.$ : $p$-value $=0.008 ; \mathrm{PM}_{2.5-10}: p$-value $\left.=0.002\right)$. This shows that the air filtration of the HVAC system in the terminal building was effective at removing particles between $1 \mu \mathrm{m}$ and $10 \mu \mathrm{m}$ in diameter.

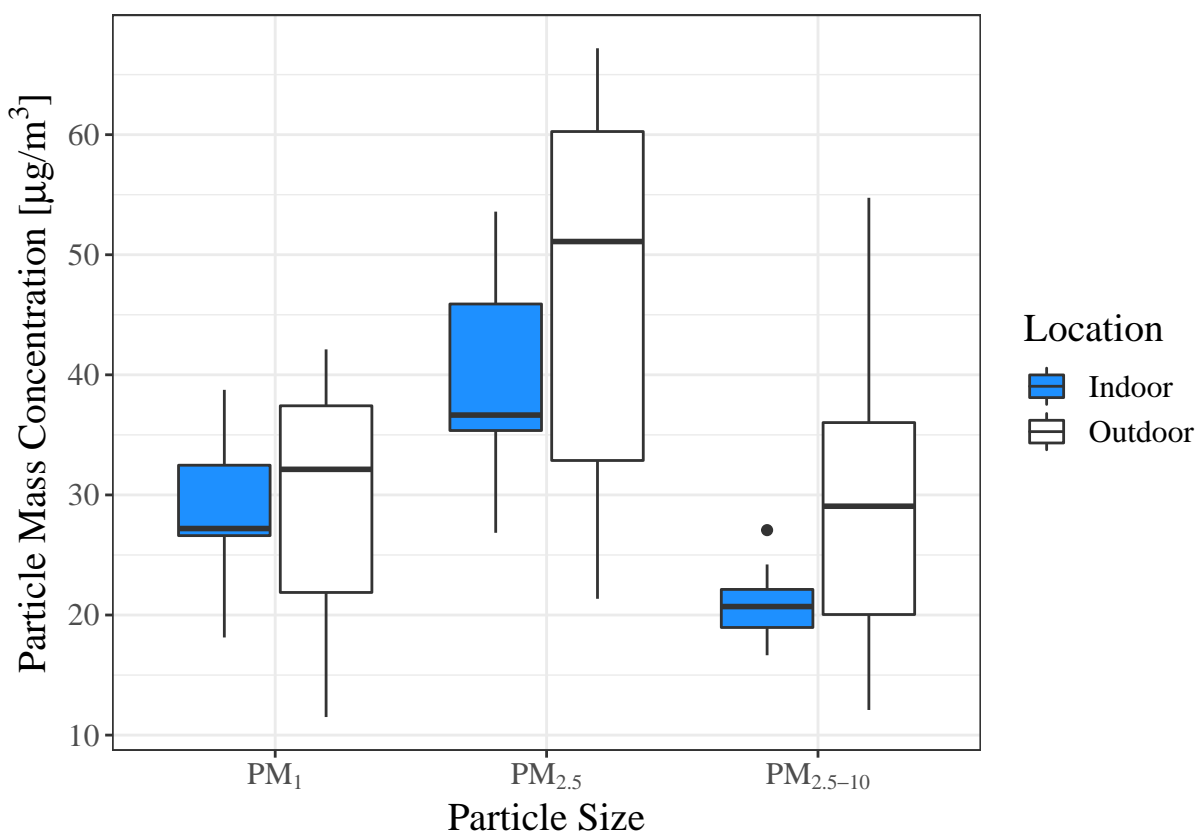

Figure 8. Comparison of indoor and outdoor particle mass concentrations of different size groups.

\subsection{I/O Ratio}

As illustrated by the time series in Figures 5-7, it was hypothesized that a time lag exists between the change of indoor and outdoor $\mathrm{PM}_{1}$ and $\mathrm{PM}_{2.5}$ concentration levels. However, no apparent correlation was observed in Figure 7 for $\mathrm{PM}_{2.5-10}$. Cross-correlation of the indoor and outdoor $\mathrm{PM}_{1}$ and $\mathrm{PM}_{2.5}$ is shown in Figure 9, and the results suggest that the outdoor $\mathrm{PM}_{1}$ lagged 15 min behind indoor values, whereas outdoor $\mathrm{PM}_{2.5}$ lagged $30 \mathrm{~min}$ behind indoor values.

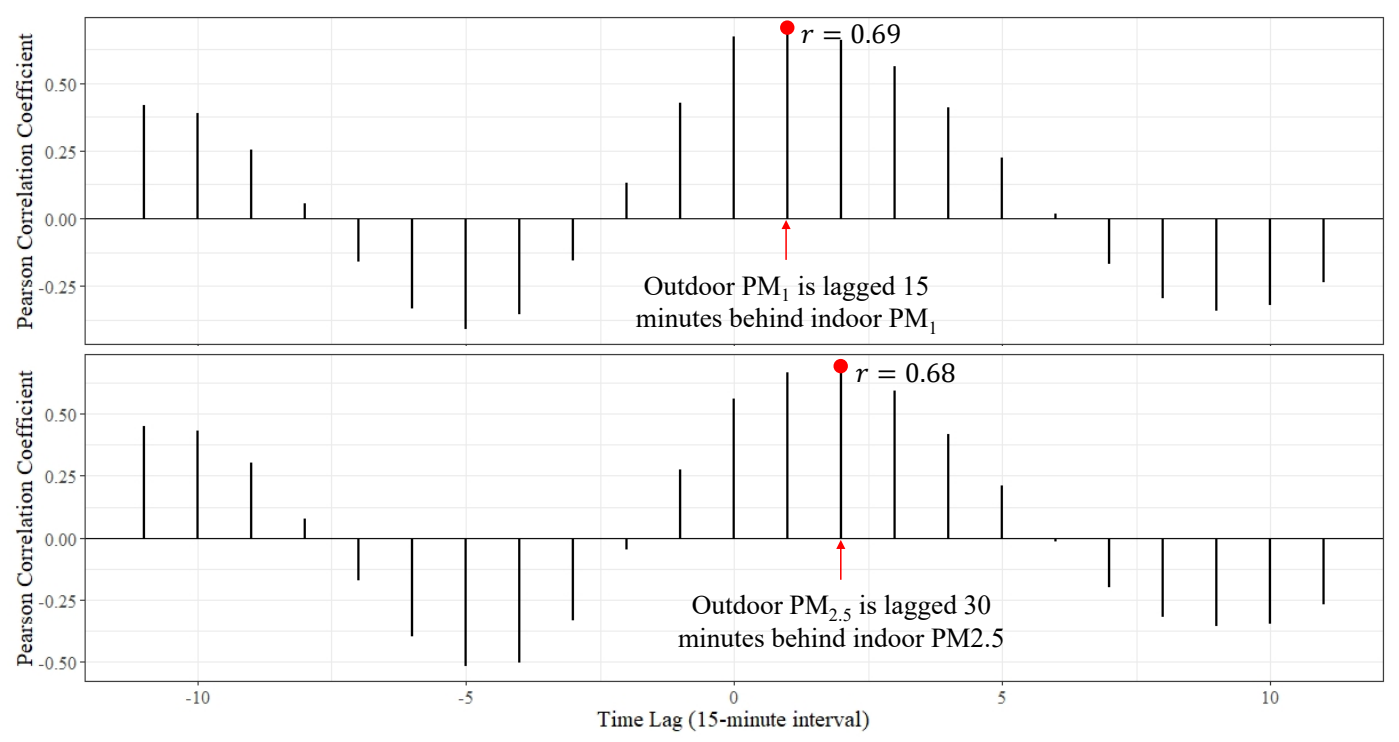

Figure 9. Cross-correlation of indoor and outdoor $\mathrm{PM}_{1}$ and $\mathrm{PM}_{2.5}$. 
The I/O ratios for $\mathrm{PM}_{1}$ and $\mathrm{PM}_{2.5}$ were estimated using linear regression with the appropriate time lags. Using outdoor particle concentration $x_{t}^{\text {out }}$ as a predictor, the indoor concentration $x_{t}^{\text {in }}$ can be estimated using Equation (2):

$$
x_{t+i}^{i n}=a_{0}+a_{1} x_{t}^{o u t}
$$

where $a_{1}$ is the I/O ratio, $a_{0}$ is the contribution from indoor source, and $i$ is the time lag in minutes.

Table 4 shows the estimated I/O ratios for $\mathrm{PM}_{1}$ and $\mathrm{PM}_{2.5}$. The variations of outdoor $\mathrm{PM}_{1}$ and $\mathrm{PM}_{2.5}$ concentrations appear to account for $41.6 \%$ and $32.5 \%$ of the change of indoor $\mathrm{PM}_{1}$ and $\mathrm{PM}_{2.5}$ concentrations respectively.

Table 4. Estimated I/O ratio using linear regression.

\begin{tabular}{ccccc}
\hline Particle Size & Time Lag (min) & Intercept & I/O Ratio & $\boldsymbol{R}^{\mathbf{2}}$ \\
\hline $\mathrm{PM}_{1}$ & 15 & 16.357 & 0.416 & 0.521 \\
$\mathrm{PM}_{2.5}$ & 30 & 24.676 & 0.325 & 0.542 \\
\hline
\end{tabular}

The traditional residential infiltration model (e.g., [39]) was not used in this study. That infiltration model was historically used for single family residences and took advantage of the fact that there were obvious indoor sources of PM, as seen by short-term peaks in the time series whose rising values were censored. However, in a large building such as an airport terminal, the indoor sources of $\mathrm{PM}_{1}$ and $\mathrm{PM}_{2.5}$ were not as obvious as in residences, and such sources were also diluted by relatively large volumes of building ventilation air. This was confirmed by the fact that the criteria for censoring of rising peak values used in the residential infiltration models [39] did not exclude any of the values observed in this study; i.e., there were no significant rising peaks in the data. Therefore it could not be assumed that the major effect of indoor source contributions over a given time period was removed, an assumption that was central to the censored infiltration model [39]. As an alternative, the association between the 15-min average indoor concentration and an appropriately lagged outdoor concentration was examined based on the results of cross-correlation analysis, as shown in Figure 9. This approach still provided insight into the significance of infiltrated outdoor PM on indoor PM levels with a limited amount of data.

\subsection{ANCOVA}

The effect of aircraft and passenger traffic on the indoor particle concentration was evaluated using ANCOVA. The total numbers of arriving and departing aircraft and passengers were converted to categorical factors, as defined in Table 5. Due to the relatively short data collection period, the creation of these categories was based on the traffic during the air quality measurement sessions (as marked in Figure 10) as opposed to the entire 24-h traffic volume.

Table 5. Aircraft and passenger traffic categories.

\begin{tabular}{ccc}
\hline Category & Aircraft Traffic (movement/hour) & Passenger Traffic (movement/hour) \\
\hline High & $>12$ & $>1200$ \\
Low & $\leq 12$ & $\leq 1200$ \\
\hline
\end{tabular}

Both "aircraft traffic" (impact from outdoor) and "passenger traffic" (impact from indoor) were categorical factors (as defined in Table 5). Given the time lags obtained between indoor and outdoor $\mathrm{PM}_{1}$ and $\mathrm{PM}_{2.5}$, and considering that the aircraft and passenger traffic data were only given in hourly totals, a one-hour lag was used for factor "aircraft traffic". The indoor and outdoor $\mathrm{PM}_{1}, \mathrm{PM}_{2.5}$, and $\mathrm{PM}_{2.5-10}$ from the previous hour $\left(\mathrm{PM}_{1, \mathrm{t}-1}, \mathrm{PM}_{2.5, \mathrm{t}-1}\right.$ and $\left.\mathrm{PM}_{2.5-10, \mathrm{t}-1}\right)$ were included as continuous variables. The ANCOVA results are shown in Table 6. It appears that "aircraft traffic" contributed significantly to the indoor fine particles $\mathrm{PM}_{1}$ and $\mathrm{PM}_{2.5}$, whereas "passenger traffic" had a significant influence on coarse indoor particles. 


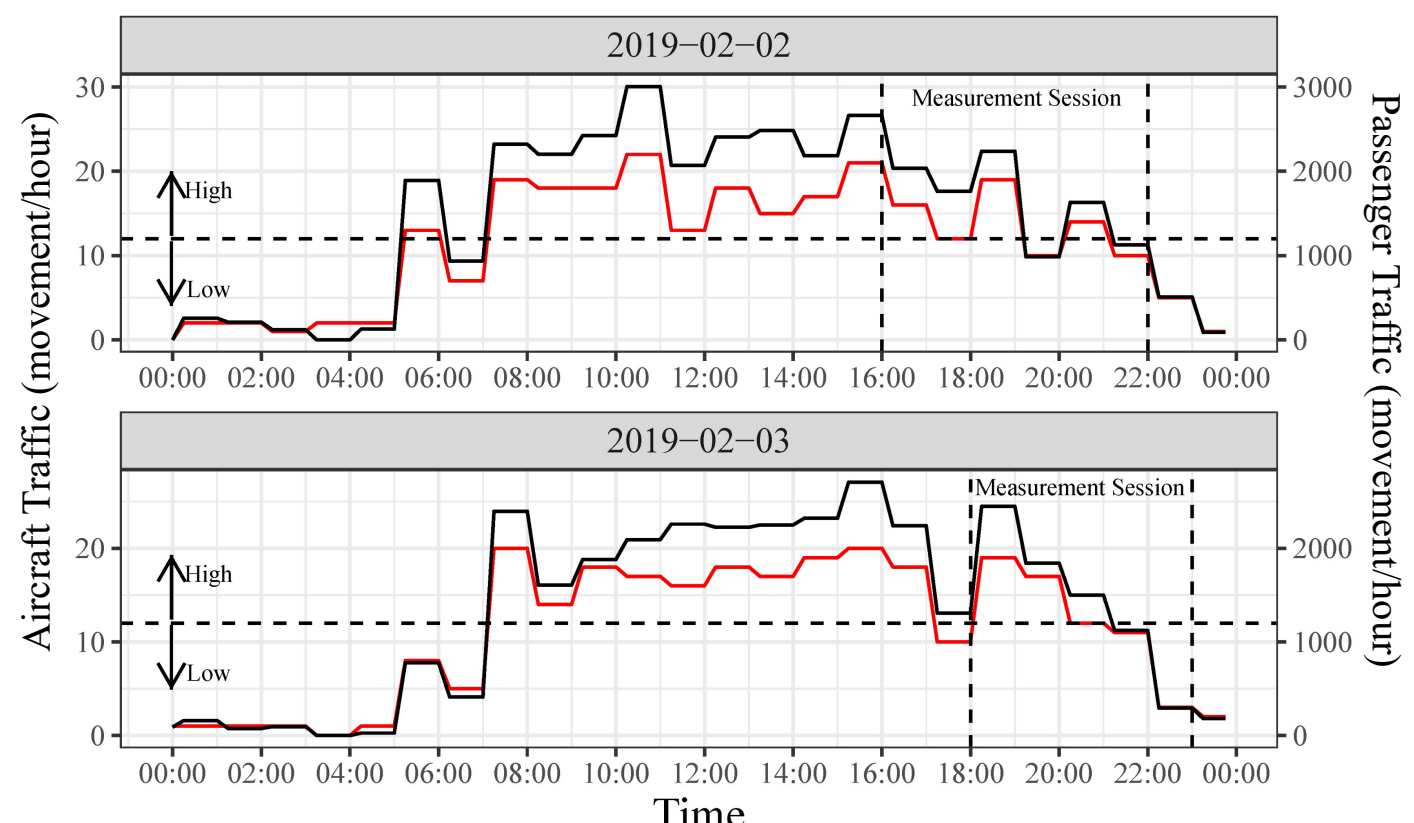

Figure 10. The aircraft and passenger traffic time series of the selected two days. The shaded area shows the period when air quality data were collected at the terminal.

Table 6. ANCOVA for the effects of aircraft and passenger traffic on indoor particle concentrations.

\begin{tabular}{|c|c|c|c|c|}
\hline Particle Size & Factor & $\mathrm{SS}^{+}$ & $\mathrm{DF}^{++}$ & $p$-Value \\
\hline \multirow{5}{*}{$\mathrm{PM}_{1}$} & Outdoor $\mathrm{PM}_{1, \mathrm{t}-1}$ & 5.30 & 1 & 0.40 \\
\hline & Indoor $\mathrm{PM}_{1, \mathrm{t}-1}$ & 1.34 & 1 & 0.67 \\
\hline & Aircraft Traffic & 34.06 & 1 & $0.05^{* *}$ \\
\hline & Passenger Traffic & 8.83 & 1 & 0.29 \\
\hline & Residuals & 93.03 & 13 & \\
\hline \multirow{5}{*}{$\mathbf{P M}_{2.5}$} & Outdoor $\mathrm{PM}_{2.5, \mathrm{t}-1}$ & 12.65 & 1 & 0.41 \\
\hline & Indoor $\mathrm{PM}_{2.5, \mathrm{t}-1}$ & 4.81 & 1 & 0.61 \\
\hline & Aircraft Traffic & 69.12 & 1 & $0.07 *$ \\
\hline & Passenger Traffic & 7.93 & 1 & 0.52 \\
\hline & Residuals & 231.02 & 13 & \\
\hline \multirow{5}{*}{$\mathrm{PM}_{2.5-10}$} & Outdoor $\mathrm{PM}_{2.5-10, t-1}$ & 2.60 & 1 & 0.32 \\
\hline & Indoor $\mathrm{PM}_{2.5-10, t-1}$ & 7.43 & 1 & 0.10 * \\
\hline & Aircraft Traffic & 2.18 & 1 & 0.36 \\
\hline & Passenger Traffic & 16.57 & 1 & $0.02 * *$ \\
\hline & Residuals & 30.99 & 13 & \\
\hline
\end{tabular}

${ }^{+}$Sum of squares; ${ }^{\text {t+ }}$ degree of freedom; ${ }^{*}$ the factor is significant at $\alpha=0.1 ;{ }^{* *}$ the factor is significant at $\alpha=0.05$.

\section{Discussion}

The hypothesis tests showed that the indoor $\mathrm{PM}_{2.5}$ and $\mathrm{PM}_{2.5-10}$ were significantly lower than those outdoors, whereas the $\mathrm{PM}_{1}$ concentration was comparable to the outdoor one. The estimated $\mathrm{I} / \mathrm{O}$ ratios suggest that the air filtration system at the terminal was working effectively in removing $\mathrm{PM}_{2.5}$ as compared to the reported ratios in Ren et al. [21]. However, the removal of $\mathrm{PM}_{1}$ was less efficient. The ANCOVA results revealed that passenger traffic was a significant factor that affected the indoor coarse particle concentrations, while aircraft traffic showed significant effect on fine particles. The combined results indicate that the terminal building HVAC system is efficient at protecting the 
passengers and employees from aircraft emissions and other outdoor particles. The change in indoor fine particle concentration was largely due to aircraft traffic, which was inevitable for an airport terminal building. On the other hand, the change in indoor coarse particle concentration was largely depending on the passenger movement and the concentration from the previous hour. This also reflects the ability of the coarse particles to remain in the building at the current air exchange rate. The additional air filtration and cleaning system inside the boarding bridge may reduce the particles brought into the terminal building by arriving passengers. Increased ventilation rate could also aid the removal of existing coarse particles in the terminal building. As summarized in [42], other than the PM of outdoor origin, there were numerous potential indoor sources of PM. For a large and complex building such as the airport terminal, these sources include particle emission and resuspension, which were often linked to human activities [42]. Studies have shown that bioaerosols emitted from damp surfaces, cleaning product residues, and cooking activities could contribute to indoor PM [42]. Particle resuspension from activities such as walking and vaccuming, which are common for a terminal building, is also an important source of indoor PM [14,15,43]. The indoor measurement conducted in this study was at a single location near the boarding gate. Therefore the main activity considered was the walking of passengers and the spatial coverage was rather limited. If resources permit, future studies could consider deploying multiple sensors at various representative sites inside the terminal to investigate the different PM contributions from different locations with various activities.

This study detailed the process of gaining access to the airport terminal building to conduct air quality measurements and could be beneficial to future studies at airports. Due to time and resource constraints, the measurements were only for a short period of time and the dataset was limited. Because the PM measurements were conducted using a light scattering monitor, the high level of humidity in Jakarta also resulted in data loss. The influence of humidity on the remaining optical measurements was evaluated by calculating the I/O ratios for subsets of the data with different $\mathrm{RH}$ cutoff values, and the results showed modest changes for the I/O ratios. In addition, as can be seen from Figure 10, the peak traffic periods were not covered by this study. A permanent air quality monitoring program at the airport would allow data collection in longer terms and contributes to the growth of the airport indoor air quality knowledge base.

Author Contributions: Conceptualization, A.K. and T.L.; methodology, S.W. and T.L.; formal analysis, S.W. and T.L.; investigation, A.K. and L.M.; resources, A.K. and L.M.; data curation, L.M. and S.W.; writing-original draft preparation, A.K. and L.M.; writing-review and editing, S.W. and T.L.; visualization, S.W.; supervision, A.K. All authors have read and agreed to the published version of the manuscript.

Funding: Majority of this work was supported by the University of Washington (UW) Global Innovation Fund grant and the UW Southeast Asia Center Fund grant. Medal received partial travel support from Indonesia Endowment Fund for Education (LPDP). This work made use of equipment supported by the National Science Foundation under grant number 1852995.

Acknowledgments: We would like to thank the Human Resources and General Affairs of SHIA for granting the research team the approval to conduct the study, Heru Karyadi, and the terminal service and facility team for providing access during the daily measurement sessions in Terminal 3 and for providing the secondary data necessary to conduct the analysis. We would also like to thank the Indonesian Meteorology, Climatology, and Geophysical Agency for providing the weather data at the airport.

Conflicts of Interest: The authors declare no conflict of interest.

\section{References}

1. Kazda, A.; Caves, R.E. Airport Design and Operation; Elsevier Ltd.: Amsterdam, The Netherlands, 2007.

2. Helmis, C.G.; Assimakopoulos, V.D.; Flocas, H.A.; Stathopoulou, O.I.; Sgouros, G.; Hatzaki, M. Indoor air quality assessment in the air traffic control tower of the Athens Airport, Greece. Environ. Monit. Assess. 2008, 148, 47-60. [CrossRef] [PubMed]

3. Mokalled, T.; Gérard, J.A.; Abboud, M.; Liaud, C.; Nassreddine, R.; Calvé, S.L. An assessment of indoor air quality in the maintenance room at Beirut-Rafic Hariri International Airport. Atmos. Pollut. Res. 2018. [CrossRef] 
4. Tsakas, M.P.; Siskos, P.A. Indoor Air Quality in the Control Tower of Athens International Airport, Greece. Indoor Built Environ. 2010, 20, 284-289. [CrossRef]

5. Lee, K.; Hahn, E.J.; Robertson, H.E.; Whitten, L.; Jones, L.K.; Zahn, B. Air quality in and around airport enclosed smoking rooms. Nicotine Tob. Res. 2010, 12, 665-668. [CrossRef] [PubMed]

6. Kungskulniti, N.; Charoenca, N.; Peesing, J.; Trangwatana, S.; Hamann, S.; Pitayarangsarit, S.; Chitanondh, H. Assessment of secondhand smoke in international airports in Thailand, 2013. Tob. Control 2014, 24, 532-535. [CrossRef]

7. Hsu, H.H.; Adamkiewicz, G.; Houseman, E.A.; Vallarino, J.; Melly, S.J.; Wayson, R.L.; Spengler, J.D.; Levy, J.I. The relationship between aviation activities and ultrafine particulate matter concentrations near a mid-sized airport. Atmos. Environ. 2012, 50, 328-337. [CrossRef]

8. Hsu, H.H.; Adamkiewicz, G.; Houseman, E.A.; Zarubiak, D.; Spengler, J.D.; Levy, J.I. Contributions of aircraft arrivals and departures to ultrafine particle counts near Los Angeles International Airport. Sci. Total Environ. 2013, 444, 347-355. [CrossRef]

9. Stacey, B. Measurement of ultrafine particles at airports: A review. Atmos. Environ. 2019, 198, 463-477. [CrossRef]

10. Hudda, N.; Gould, T.; Hartin, K.; Larson, T.V.; Fruin, S.A. Emissions from an International Airport Increase Particle Number Concentrations 4-fold at 10 km Downwind. Environ. Sci. Technol. 2014, 48, 6628-6635. [CrossRef]

11. Masiol, M.; Harrison, R.M.; Vu, T.V.; Beddows, D.C.S. Sources of sub-micrometre particles near a major international airport. Atmos. Chem. Phys. 2017, 17, 12379-12403. [CrossRef]

12. Masiol, M.; Vu, T.V.; Beddows, D.C.S.; Harrison, R.M. Source apportionment of wide range particle size spectra and black carbon collected at the airport of Venice (Italy). Atmos. Environ. 2016, 139, 56-74. [CrossRef]

13. Fanning, E.; Yu, R.C.; Lu, R.; Froines, J. Monitoring and Modeling of Ultrafine Particles and Black Carbon at the Los Angeles International Airport; Resreport 04-325; Unviersity of California: Los Angeles, CA, USA, 2007. Available online: http:/ / citeseerx.ist.psu.edu/viewdoc/download?doi=10.1.1.483.5919\&rep=rep1\&type= pdf (accessed on 5 March 2019).

14. Qian, J.; Peccia, J.; Ferro, A.R. Walking-induced particle resuspension in indoor environments. Atmos. Environ. 2014, 89, 464-481. [CrossRef]

15. Tian, Y.; Sul, K.; Qian, J.; Mondal, S.; Ferro, A.R. A comparative study of walking-induced dust resuspension using a consistent test mechanism. Indoor Air 2014, 24, 592-603. [CrossRef] [PubMed]

16. Johnson, G.R.; Mazaheri, M.; Ristovski, Z.D.; Morawska, L. A Plume Capture Technique for the Remote Characterization of Aircraft Engine Emissions. Environ. Sci. Technol. 2008, 42, 4850-4856. [CrossRef]

17. Tunnicliffe, W.S.; O’Hickey, S.P.; Fletcher, T.J.; Miles, J.F.; Burge, P.S.; Ayres, J.G. Pulmonary function and respiratory symptoms in a population of airport workers. Occup. Environ. Med. 1999, 56, 118-123. [CrossRef]

18. Yang, C.Y.; Wu, T.N.; Wu, J.J.; Ho, C.K.; Chang, P.Y. Adverse Respiratory and Irritant Health Effects in Airport Workers in Taiwan. J. Toxicol. Environ. Heal. Part A 2003, 66, 799-806. [CrossRef]

19. Møller, K.L.; Thygesen, L.C.; Schipperijn, J.; Loft, S.; Bonde, J.P.; Mikkelsen, S.; Brauer, C. Occupational Exposure to Ultrafine Particles among Airport Employees-Combining Personal Monitoring and Global Positioning System. PLoS ONE 2014, 9, e106671. [CrossRef]

20. Zanni, S.; Lalli, F.; Foschi, E.; Bonoli, A.; Mantecchini, L. Indoor Air Quality Real-Time Monitoring in Airport Terminal Areas: An Opportunity for Sustainable Management of Micro-Climatic Parameters. Sensors 2018, 18, 3798. [CrossRef]

21. Ren, J.; Cao, X.; Liu, J. Impact of atmospheric particulate matter pollutants to IAQ of airport terminal buildings: A first field study at Tianjin Airport, China. Atmos. Environ. 2018, 179, 222-226. [CrossRef]

22. Brunekreef, B.; Forsberg, B. Epidemiological evidence of effects of coarse airborne particles on health. Eur. Respir. J. 2005, 26, 309-318. [CrossRef]

23. Deng, Q.; Deng, L.; Miao, Y.; Guo, X.; Li, Y. Particle deposition in the human lung: Health implications of particulate matter from different sources. Environ. Res. 2019, 169, 237-245. [CrossRef] [PubMed] 
24. Airports Council International. Preliminary World Airport Traffic Rankings Released; Airports Council International: Montreal, QC, Canada, 2019. Available online: https://aci.aero/news/2019/03/13/ preliminary-world-airport-traffic-rankings-released/ (accessed on 5 October 2019).

25. OAG Aviation Worldwide. Megahubs International Index 2018-The World's Most Internationally Connected Airports; OAG Aviation Worldwide: Luton, UK, 2018. Available online: https: / /www.oag.com/hubfs/Free_Reports/Megahubs/2018/Megahubs_International_Index_2018.pdf? hsCtaTracking=cb970431-e381-4ada-b54b-b168f98d9eb7\%7Cf52e0462-7e9f-4091-a2e7-91d2eda51d07 (accessed on 5 October 2019).

26. Particles Plus, Inc. 7301-AQM and 7302-AQM Remote Air Quality and Environmental Monitor; Particles Plus, Inc.: Stoughton, MA, USA, 2019. Available online: https:/ / particlesplus.com/7301-iaq-remote-particlecounter/ (accessed on 28 May 2019).

27. Thermoplastic Processes. Bev-A-Line XX Tubing; Thermoplastic Processes: Georgetown, DE, USA, 2019. Available online: http:/ / www.thermoplasticprocesses.com/excelon-extruded-plastic-products/beveragetubing/products-bev-a-line-xx-html/ (accessed on 28 May 2019).

28. BMKG. Meteorological, Climatological and Geophysical Agency; BMKG: Jakarta, Indonesia, 2019.

29. Weather Underground. Tangerang, Indonesia History; The Weather Company: Brookhaven, GA, USA, 2019. Available online: https:/ / www.wunderground.com/history/daily/id/tangerang/WIII/date (accessed on 29 May 2019).

30. Sioutas, C.; Kim, S.; Chang, M.; Terrell, L.L.; Gong Jr., H. Field evaluation of a modified DataRAM MIE scattering monitor for real-time PM2.5 mass concentration measurements. Atmos. Environ. 2000, 34, 4829-4838. [CrossRef]

31. Day, D.E.; Malm, W.C.; Kreidenweis, S.M. Aerosol Light Scattering Measurements as a Function of Relative Humidity. J. Air Waste Manag. Assoc. 2000, 50, 710-716. [CrossRef] [PubMed]

32. Chakrabarti, B.; Fine, P.M.; Delfino, R.; Sioutas, C. Performance evaluation of the active-flow personal DataRAM PM2.5 mass monitor (Thermo Anderson pDR-1200) designed for continuous personal exposure measurements. Atmos. Environ. 2004, 38, 3329-3340. [CrossRef]

33. Custom Advanced Connections. Dacron Filter Bags. Custom Advanced Connections: Webster, TX, USA, 2019. Available online: https:/ / www.customadvanced.com/dacron-filter-bags.html (accessed on 5 October 2019).

34. Hasheminassab, S.; Pakbin, P.; Delfino, R.J.; Schauer, J.J.; Sioutas, C. Diurnal and seasonal trends in the apparent density of ambient fine and coarse particles in Los Angeles. Environ. Pollut. 2014, 187, 1-9. [CrossRef]

35. Badan Standardisasi Nasional (BSN). Standar Nasional Indonesia (Indonesian National Standardization) SNI 03-6572:2001 Tata Cara Perancangan Sistem Ventilasi dan Pengkondisian Udara pada Bangunan Gedung; BSN: Jakarta, Indonesia, 2001. Available online: http:/ / staffnew.uny.ac.id/upload/132100514/pendidikan/ perencanaan-pendingin.pdf (accessed on 7 May 2019).

36. The Government of the Province of Jakarta Capital Special Territory. Jakarta Green Building User Guide; The Government of the Province of Jakarta Capital Special Territory: Jakarta, Indonesia, 2012. Available online: https:/ / greenbuilding.jakarta.go.id/index-en.html (accessed on 7 May 2019).

37. R Core Team. R: A Language and Environment for Statistical Computing; R Foundation for Statistical Computing: Vienna, Austria, 2019. Available online: https:/ / www.R-project.org/ (accessed on 7 May 2019).

38. Shapiro, S.S.; Wilk, M.B. An Analysis of Variance Test for Normality (Complete Samples). Biometrika 1965, 52, 591-611. [CrossRef]

39. Allen, R.; Larson, T.; Sheppard, L.; Wallace, L.; Liu, L.J.S. Use of Real-Time Light Scattering Data To Estimate the Contribution of Infiltrated and Indoor-Generated Particles to Indoor Air. Environ. Sci. Technol. 2003, 37, 3484-3492. [CrossRef]

40. Han, Y.; Qi, M.; Chen, Y.; Shen, H.; Liu, J.; Huang, Y.; Chen, H.; Liu, W.; Wang, X.; Liu, J.; et al. Influences of ambient air PM2.5 concentration and meteorological condition on the indoor PM2.5 concentrations in a residential apartment in Beijing using a new approach. Environ. Pollut. 2015, 205, 307-314. [CrossRef]

41. Zuo, J.; Ji, W.; Ben, Y.; Hassan, M.A.; Fan, W.; Bates, L.; Dong, Z. Using big data from air quality monitors to evaluate indoor PM2.5 exposure in buildings: Case study in Beijing. Environ. Pollut. 2018, 240, 839-847. [CrossRef] 
42. National Academies of Sciences, Engineering, and Medicine. Health Risks of Indoor Exposure to Particulate Matter; National Academies Press: Washington, DC, USA, 2016. [CrossRef]

43. Ferro, A.R.; Kopperud, R.J.; Hildemann, L.M. Source Strengths for Indoor Human Activities that Resuspend Particulate Matter. Environ. Sci. Technol. 2004, 38, 1759-1764. [CrossRef]

(C) 2020 by the authors. Licensee MDPI, Basel, Switzerland. This article is an open access article distributed under the terms and conditions of the Creative Commons Attribution (CC BY) license (http:// creativecommons.org/licenses/by/4.0/). 